\title{
Intra-racial disparities: The effect of poverty and obesity on the psychosocial profile of Mexican-American children
}

\author{
Marie Leiner, ${ }^{1}$ Jesus Peinado, ${ }^{1}$ Maria Theresa Villanos, ${ }^{1}$ Ricardo Uribe, ${ }^{2}$ Indu Pathak ${ }^{1}$
}

Original article

\section{ABSTRACT}

\section{Introduction}

The high prevalence of obesity among children of Mexican descent, living in either Mexico or the United States (US), might indicate they are at a higher risk when compared to other groups. Previous mental health studies have had conflicting outcomes, which may be the result of considering these children as a homogeneous group (by race or ethnicity) instead of considering intra-racial group disparities (e.g. socio-economic status, adversities).

\section{Objective}

To compare the psychosocial profile by weight category (normal weight, overweight, or obese) of impoverished Mexican descendent children in a clinical setting.

\section{Method}

The study design was cross sectional. Information was retrieved from medical records ( $N=2237$ ) that were obtained from five university-based clinics in a large metropolitan area on the US-Mexico border from May 2009 to August 2010.

\section{Results}

Psychosocial and behavioral problems were present among this intra-racial group of Mexican-American children, with higher scores in the overweight and obese children than in the normal-weight children.

\section{Discussion and conclusion}

Intra-racial differences among obese and overweight children could account for variation in results regarding the mental health of Mexican American children.

Considering intra-racial group disparities when providing healthcare may improve delivery and promote better mental and health outcomes because some groups may need more attention than others. In addition, considering these groups when designing studies, may improve the accuracy and precision of study result interpretations.

Key words: Health disparities, mental health, obesity, overweight, children, adolescent.

\section{RESUMEN}

\section{Introducción}

La alta prevalencia de obesidad en niños de origen mexicano, ya sea en los Estados Unidos o en México, puede indicar la posibilidad de mayores riesgos al compararlos con otros grupos étnicos. Estudios previos sobre su salud mental han mostrado resultados contradictorios, que pueden deberse por considerar a estos niños como un grupo homogéneo (de acuerdo con el grupo étnico) en lugar de hacerlo considerando la existencia de diferencias intra-raciales (ej. nivel socioeconómico, exposición a disparidades).

\section{Objetivo}

Comparar el perfil psicosocial de niños méxico-americanos viviendo en la pobreza en los Estados Unidos de acuerdo a su categoría de peso (normal, sobrepeso, obesidad).

\section{Método}

El estudio es transversal. La información fue recolectada a partir de records médicos ( $N=2237)$ obtenidos en cinco clínicas en una ciudad metropolitana. Resultados: Los resultados indican mayores problemas psicosociales y de comportamiento en este grupo intrarracial de niños México-Americanos con sobrepeso y obesidad al compararlos con los de peso normal.

\section{Discusión y conclusión}

Las posibles diferencias intra-raciales de estos niños confrontando obesidad y sobrepeso y viviendo en la pobreza, pueden explicar las diferencias reportadas en algunos estudios.

Considerar la existencia de grupos intra-raciales al proveer salud puede mejorar los resultados, ya que algunos grupos pueden necesitar más atención que otros. De forma adicional, considerar estos sub-grupos al diseñar estudios puede mejorar la exactitud y precisión de la interpretación de resultados.

Palabras clave: Disparidades, salud mental, obesidad, sobrepeso, población pediátrica.

2 Paul L. Foster School of Medicine El Paso, Texas, USA.

Correspondence: Marie Leiner, Ph.D., Research Associate Professor, Department of Pediatrics, Texas Tech University Health Sciences Center, 4800 Alberta, El Paso, Texas, 79905, USA. Tel: 915215 - 5832. E-mail: marie.leiner@ttuhsc.edu

Received first version: January 15, 2016. Second version: April 18, 2016. Accepted: May 6, 2016 


\section{INTRODUCTION}

Obese children have different rates of comorbidity with other physical disorders, including chronic diseases such as high blood pressure, diabetes, and musculoskeletal disorders (especially osteoarthritis) when compared to normal-weight children. ${ }^{1-7}$ These comorbidities occur similarly across all ethnic groups; however, Mexican-American children seem to have a higher risk of obesity than other groups. ${ }^{8,9}$ Although the determinants of childhood obesity for children of Mexican descent are likely to be different depending on whether they reside in Mexico or in the United States (US), the prevalence is similar regardless of the country of residence (US or Mexico). The prevalence of obesity (2009-2010) among Mexican-American children aged 6-11 years living in the US was 39.0\% (overweight) and $22.1 \%$ (obese). Among adolescents $12-19$ years, 30.0\% were overweight and $16.1 \%$ were obese. ${ }^{10}$ The Mexico National Survey of Health and Nutrition 2011-2012 ${ }^{11}$ reported that among children 5 to 11 years old, 19.8\% were overweight and $14.6 \%$ were obese. For adolescents aged 12-18 years, according to ENSAUT 2012, 21.6\% were overweight and $13.3 \%$ were obese.

Similar comorbid conditions tend to cluster within ethnic or racial groups, suggesting the possibility that environmental factors may play a role. ${ }^{12}$ Even though Mexican children living in the two different countries (US or Mexico) confront different economic, social, and safety conditions, poor children in either country might be exposed to very similar patterns of disparities and disadvantages. Some authors have explained this phenomenon by stratifying ethnic and racial groups into further sub-groups (intra-racial groups) whose members range from those who are affluent (higher socioeconomic status) to those who confront numerous disparities. ${ }^{13,14}$ The focal point of interest in these findings is that intra-racial differences provide a better perspective of the physical and mental health of groups rather than simply a consideration by ethnicity or race alone. In fact, these considerations can explain why previous studies of the same racial or ethnic groups have produced different results (e.g., an association or its absence), as well as apparent discrepancies. For example, there have been conflicting results from research exploring the relationship between obesity and mental health within a sample population (e.g., within a single racial group), with studies either reporting a relationship ${ }^{15-17}$ or lack thereof. ${ }^{18-21}$ For example, studies in Mexican-American children investigating the relationship between obesity and mental health have shown varying results depending on the subgroup analyzed, ${ }^{22}$ including depression $^{23}$ or impulse control disorders, only among those with extremely high body mass index $(\mathrm{BMI})^{24}$ or no negative effects for obese affluent Mexican children. ${ }^{25}$

We hypothesized that these differences may be caused by the inadvertent inclusion, in some of these studies, of specific intra-racial groups without the proper analysis. Our study investigated the relationship between weight status (i.e., obese, overweight, or normal) and the psychosocial profile of Mexican American children and included only children who belong to a specific intra-racial group (i.e., children living in poverty in the US).

\section{METHOD \\ Study design}

The study design was cross sectional.

\section{Participants}

Information was retrieved from medical records $(N=2237)$ that were obtained from five university-based clinics in a large metropolitan area on the US-Mexico border from May 2009 to August 2010. Data were extracted for individuals who met the following criteria: aged 6-16 years; of Mexican-American origin; and enrolled in Medicaid, state insurance, or lacking insurance. In addition, they had English or Spanish parents who had provided responses to the P+CBCL, and they had at least three recent clinically measured BMIs in the last nine months. Medicaid, state insurance, or lack of insurance participation was considered an indicator of low socioeconomic status (SES). Exclusion criteria included children with a history of chronic or congenital disease as well as children with highly variable height or weight measurements (e.g., exaggerated increase in weight over short periods). Exclusion of cases was selected because in our experience this discrepancy is mainly caused by measurement or data input error (excluded records represented less than 110 records 5\%).

\section{Variables}

Potential confounders included age and gender, socioeconomic, and health status. To reduce the effect of confounders, multivariable analysis was utilized stratifying by age and gender. SES and health status were controlled by the inclusion criteria.

\section{Measures}

The independent variable of this study (normal weight, overweight or obese) was computed by calculating BMI. BMI was calculated for each child using the formula weight/height. ${ }^{2}$ We categorized normal weight as children with a BMI $\geq 10$ percentile to $<85$ percentile), overweight as children with a $\mathrm{BMI} \geq 85$ percentile to $<95$ percentile, and obese as children with a BMI $\geq 95$ percentile) using charts stratified by age and gender that are published by the US Centers for Diseases Control (CDC). 
Table 1. Problem raw scores for children of Mexican-American descent by gender and weight category

\begin{tabular}{|c|c|c|c|c|c|c|}
\hline \multirow[b]{2}{*}{ Problem } & \multicolumn{2}{|c|}{$6-9$ years } & \multicolumn{2}{|c|}{$10-13$ years } & \multicolumn{2}{|c|}{$14-16$ years } \\
\hline & $\begin{array}{c}\text { Boys } \\
N(S D)\end{array}$ & $\begin{array}{c}\text { Girls } \\
N(S D)\end{array}$ & $\begin{array}{c}\text { Boys } \\
N(S D)\end{array}$ & $\begin{array}{c}\text { Girls } \\
N(S D)\end{array}$ & $\begin{array}{c}\text { Boys } \\
N \text { (SD) }\end{array}$ & $\begin{array}{c}\text { Girls } \\
N(S D)\end{array}$ \\
\hline \multicolumn{7}{|l|}{ Internalizing } \\
\hline Normal weight & $1.61(0.44)$ & $1.61(0.44)$ & $1.62(0.44)$ & $1.69(0.45)$ & $1.51(0.43)$ & $1.60(0.42)$ \\
\hline Overweight & $1.55(0.45)$ & $1.58(0.43)$ & $1.74(0.42)$ & $1.73(0.53)$ & $1.64(0.50)$ & $1.85(0.40)$ \\
\hline Obese & $1.66(0.46)$ & $1.65(0.43)$ & $1.69(0.44)$ & $1.79(0.46)$ & $1.78(0.45)$ & $1.74(0.45)$ \\
\hline \multicolumn{7}{|l|}{ Externalizing } \\
\hline Normal weight & $1.67(0.47)$ & $1.50(0.43)$ & $1.61(0.49)$ & $1.63(0.49)$ & $1.61(0.46)$ & $1.53(0.47)$ \\
\hline Overweight & $1.58(0.44)$ & $1.50(0.43)$ & $1.68(0.49)$ & $1.68(0.47)$ & $1.87(0.36)$ & $1.81(0.40)$ \\
\hline Obese & $1.66(0.47)$ & $1.53(0.46)$ & $1.56(0.47)$ & $1.66(0.43)$ & $1.73(0.48)$ & $1.71(0.52)$ \\
\hline \multicolumn{7}{|l|}{ Total } \\
\hline Normal weight & $2.23(0.48)$ & $2.10(0.49)$ & $2.18(0.48)$ & $2.17(0.51)$ & $2.10(0.50)$ & $2.06(0.49)$ \\
\hline Overweight & $2.15(0.49)$ & $2.11(0.47)$ & $2.27(0.49)$ & $2.18(0.57)$ & $2.39(0.36)$ & $2.38(0.33)$ \\
\hline Obese & $2.24(0.51)$ & $2.16(0.50)$ & $2.20(0.48)$ & $2.28(0.47)$ & $2.24(0.49)$ & $2.22(0.49)$ \\
\hline \multicolumn{7}{|c|}{ Anxious/Depressed } \\
\hline Normal weight & $1.34(0.35)$ & $1.33(0.34)$ & $1.33(0.36)$ & $1.38(0.37)$ & $1.20(0.31)$ & $1.23(0.30)$ \\
\hline Overweight & $1.30(0.35)$ & $1.29(0.35)$ & $1.40(0.35)$ & $1.43(0.44)$ & $1.32(0.38)$ & $1.42(0.35)$ \\
\hline Obese & $1.36(0.37)$ & $1.36(0.34)$ & $1.35(0.38)$ & $1.50(0.39)$ & $1.36(0.38)$ & $1.35(0.40)$ \\
\hline \multicolumn{7}{|c|}{ Withdrawn/Depressed } \\
\hline Normal weight & $1.18(0.25)$ & $1.15(0.26)$ & $1.18(0.26)$ & $1.21(0.30)$ & $1.22(0.32)$ & $1.20(0.30)$ \\
\hline Overweight & $1.12(0.25)$ & $1.10(0.21)$ & $1.15(0.26)$ & $1.15(0.26)$ & $1.15(0.26)$ & $1.15(0.26)$ \\
\hline Obese & $1.15(0.26)$ & $1.15(0.26)$ & $1.15(0.26)$ & $1.15(0.26)$ & $1.15(0.26)$ & $1.15(0.26)$ \\
\hline \multicolumn{7}{|c|}{ Somatic Complaints } \\
\hline Normal weight & $1.25(0.30)$ & $1.28(0.32)$ & $1.27(0.34)$ & $1.31(0.34)$ & $1.18(0.26)$ & $1.27(0.32)$ \\
\hline Overweight & $1.25(0.30)$ & $1.31(0.34)$ & $1.29(0.35)$ & $1.36(0.40)$ & $1.28(0.38)$ & $1.45(0.38)$ \\
\hline Obese & $1.31(0.35)$ & $1.27(0.33)$ & $1.42(0.36)$ & $1.25(0.30)$ & $1.42(0.36)$ & $1.37(0.33)$ \\
\hline \multicolumn{7}{|l|}{ Social Problems } \\
\hline Normal weight & $1.25(0.30)$ & $1.28(0.32)$ & $1.27(0.34)$ & $1.31(0.34)$ & $1.18(0.26)$ & $1.27(0.32)$ \\
\hline Overweight & $1.25(0.33)$ & $1.31(0.34)$ & $1.29(0.35)$ & $1.36(0.40)$ & $1.28(0.38)$ & $1.36(0.37)$ \\
\hline Obese & $1.31(0.35)$ & $1.27(0.33)$ & $1.34(0.34)$ & $1.35(0.36)$ & $1.42(0.36)$ & $1.37(0.33)$ \\
\hline \multicolumn{7}{|l|}{ Thought Problems } \\
\hline Normal weight & $1.21(0.30)$ & $1.15(0.24)$ & $1.20(0.29)$ & $1.18(0.28)$ & $1.17(0.27)$ & $1.13(0.23)$ \\
\hline Overweight & $1.22(0.29)$ & $1.16(0.29)$ & $1.25(0.33)$ & $1.15(0.31)$ & $1.28(0.34)$ & $1.23(0.28)$ \\
\hline Obese & $1.18(0.29)$ & $1.16(0.27)$ & $1.21(0.31)$ & $1.24(0.31)$ & $1.28(0.33)$ & $1.25(0.32)$ \\
\hline \multicolumn{7}{|l|}{ Attention Problems } \\
\hline Normal weight & $1.54(0.40)$ & $1.34(0.37)$ & $1.45(0.41)$ & $1.35(0.38)$ & $1.35(0.37)$ & $1.29(0.34)$ \\
\hline Overweight & $1.47(0.40)$ & $1.36(0.37)$ & $1.55(0.41)$ & $1.38(0.42)$ & $1.56(0.41)$ & $1.38(0.42)$ \\
\hline Obese & $1.52(0.39)$ & $1.37(0.37)$ & $1.40(0.40)$ & $1.39(0.40)$ & $1.45(0.40)$ & $1.45(0.45)$ \\
\hline \multicolumn{7}{|c|}{ Rule Breaking Behavior } \\
\hline Normal weight & $1.25(0.30)$ & $1.13(0.21)$ & $1.21(0.30)$ & $1.20(0.29)$ & $1.27(0.34)$ & $1.15(0.25)$ \\
\hline Overweight & $1.21(0.28)$ & $1.15(0.26)$ & $1.29(0.33)$ & $1.22(0.30)$ & $1.39(0.38)$ & $1.38(0.34)$ \\
\hline Obese & $1.26(0.32)$ & $1.15(0.25)$ & $1.21(0.30)$ & $1.18(0.26)$ & $1.34(0.34)$ & $1.29(0.40)$ \\
\hline \multicolumn{7}{|c|}{ Aggressive Behavior } \\
\hline Normal weight & $1.56(0.43)$ & $1.43(0.40)$ & $1.51(0.45)$ & $1.55(0.45)$ & $1.47(0.40)$ & $1.45(0.42)$ \\
\hline Overweight & $1.47(0.42)$ & $1.40(0.38)$ & $1.56(0.45)$ & $1.59(0.44)$ & $1.70(0.35)$ & $1.64(0.38)$ \\
\hline Obese & $1.54(0.45)$ & $1.46(0.42)$ & $1.46(0.43)$ & $1.57(0.42)$ & $1.58(0.45)$ & $1.62(0.47)$ \\
\hline
\end{tabular}

\section{$\mathrm{P}+\mathrm{CBCL}$}

The P+CBCL is a pictorial version of the Child Behavior Checklist (CBCL), ${ }^{26}$ which has been shown to be beneficial among those with communication disparities, such as language, education, and literacy. ${ }^{27}$ The $\mathrm{P}+\mathrm{CBCL}$ is an exact version of the original written $\mathrm{CBCL}$ but include visuals (pictograms) to help parents better understand and respond to the questions. It includes 120 behavioral and emotional problem items that assess a child's behavior on a 3-level scale for rating the extent to which a parent perceives each item in their child $(0=$ not true, $1=$ somewhat or sometimes true, 2 = very true or often true). According to the authors of the CBCL, factor analysis of the CBCL items yields eight syndromes: three syndromes (Withdrawn, Somatic Complaints, Anxious/Depressed) load on the broadband inter- 
Leiner et al.

Table 2. Effect sizes $\left(\eta^{2}\right)$ for weight status; gender, and age on $P+C B C L$ transformed scores

\begin{tabular}{|c|c|c|c|c|}
\hline Problem & Weight status & Age & Gender & Weight by age \\
\hline Internalizing & $.010^{\circ b}$ & $<.010^{\mathrm{A} 13}$ & & $<.010 \mathrm{O}, \mathrm{A} 16$ \\
\hline Externalizing & $<.010^{\circ b}$ & $<.010^{\mathrm{A} 16}$ & & $<.01^{\mathrm{Ov}, \mathrm{A} 16}$ \\
\hline Total & $.010^{\mathrm{ob}}$ & $<.010^{\mathrm{A} 13}$ & & $<.01^{\mathrm{Ov}, \mathrm{A} 13}$ \\
\hline Anxious/depressed & $<.010^{\circ b}$ & $<.010^{\mathrm{A} 13}$ & & $<.011^{\mathrm{Ov}, \mathrm{A} 13}$ \\
\hline Withdrawn/depressed & $<.010^{\circ b}$ & $.024^{\mathrm{A} 16}$ & & $<.01^{\mathrm{Ob}, \mathrm{A} 13}$ \\
\hline Somatic complaints & $.010^{\circ b}$ & & & \\
\hline Social problems & $.010^{\mathrm{ob}}$ & & & \\
\hline Thought problems & $<.010^{\circ r}$ & & & \\
\hline Attention problems & & & $.012^{M}$ & \\
\hline Rule breaking & $<.010^{\circ \mathrm{r}}$ & $.013^{\mathrm{A} 16}$ & $<.010^{M}$ & $<.011^{\mathrm{Ov}, \mathrm{A} 13}$ \\
\hline \multicolumn{5}{|l|}{ Behavior } \\
\hline Aggressive behavior & & $<.010^{\mathrm{A} 16}$ & & $<.010 \mathrm{Ob}, \mathrm{A} 16$ \\
\hline
\end{tabular}

Only effects with $p<.01$ are included in this table.

Abbreviations: Ov = Overweight Higher, $\mathrm{Ob}=$ Obese higher, $\mathrm{F}=$ Female higher, $\mathrm{M}=$ Male higher, $\mathrm{A} 9=\mathrm{Age}$ 6-9 higher, $\mathrm{A} 13$ = Age 10-13 higher, $\mathrm{A} 16=$ Age 14-16 higher.

nalizing factor, two (Rule-Breaking and Aggressive) load on the broadband Externalizing factor, and the other three (Social Problems, Thought Problems, and Attention Problems) do not load differentially on either broadband factor. A Total Problems score is computed by summing all problem items. This assessment has reported a high test-retest reliability (e.g., mean $\mathrm{r}=0.90 \mathrm{SD}=0.03$ for empirically based scales) and strong internal consistency (e.g., Cronbach alpha $=0.97$ for Total Problems score). Higher scores on these scales are associated with more psychosocial and behavioral problems. Raw scores are converted to $\mathrm{T}$ scores to determine scores in the normal and clinical range. T scores of 65 and higher are considered the clinical/subclinical cutoff points for the syndrome scales; 60 and higher for total and problems subscales.

\section{Statistical analysis}

Categorical data analysis was reported using means and standard deviations.

Statistical differences on multiple continuous dependent variables (MANCOVA) by an independent grouping variable, while controlling for a third variable called the covariate, are suggested for this type of analysis in other studies using similar data. ${ }^{28-30}$

Multivariate ANCOVAs (MANCOVAs), all of which had a 3 (weight category) $\times 2$ (gender) $\times 3$ (age groups 6-9, 10-13, 14-16) design were run for internalizing and externalizing problems and the eight empirically based syndromes. Alpha was set at $p<.01$ to take into account the multiple analyses.

Effect sizes, measured by partial Eta squared (ES), were characterized using Cohen's ${ }^{31}$ criteria (small $=.01$ to .06 , medium $=.06$ to .14 , large $>.14$ ).

Statistical analysis was conducted using Statistical Package for the Social Sciences (SPSS) V20.0.
The study received institutional review board approval.

\section{RESULTS}

This study included 2237 patients, with 1108 (49.5\%) girls and 1129 (50.5\%) boys. A total of 1292 (57.8\%) participants had normal weight, $353(15.8 \%)$ were overweight, and 592 $(26.5 \%)$ were obese. The mean age was 9.92 years $(S D=3.01)$.

\section{Effects of weight category, gender, and age in the $\mathrm{P}+\mathrm{CBCL}$ transformed raw scores}

The eight $\mathrm{P}+\mathrm{CBCL}$ subscales were not normally distributed; therefore, a transformation was performed with a logarithmic transformation that included adding the value of one to each subscale because some individuals had values of zero, precluding logarithmic transformation. The transformed raw scores for the main syndromes are displayed in table 1 by weight category, age group, and gender. In table 2, partial effect sizes (ES) values for all significant effects $(p<.01)$ are displayed in the MANCOVA on P+CBCL transformed scores. As shown in table 2, main effects for weight categories were found for six problem scales as well as Internalizing, Externalizing and Total problems (all ESs $\leq .02$ ). In all scales, obese children had the highest scores, with the exception of Thought and Rule-Breaking problem scales. For these categories, overweight children obtained the highest scores.

Significant age effects were found for seven scales (all ES < .03). Children aged 10-13 years had higher scores than younger or older groups for Internalizing, Total, and Anxious/Depressed Problems. Adolescents 14-16 years old had higher scores for Externalizing, Withdrawn Depressed, Rule Breaking, and Aggressive Behavior problems.

Significant gender effects were found in two scales. Males scored higher than girls in Attention and Rule Break- 
Intra-racial disparities: Poverty, obesity and mental health of Mexican-American children

ing problems. The only significant interaction involved weight status by age group (all seven scales ES <.01). Internalizing and Externalizing problem scores were higher in overweight children in the 13-16 years old age group. Total, Anxious/Depressed, and Rule Breaking problems scores were highest in the overweight children aged 10-13 years old. Withdraw/Depressed problem scale scores were highest among obese children in the 10-13 years old age group, and Aggressive problem scores were the highest in obese children aged 13-16 years old.

\section{DISCUSSION AND CONCLUSION}

The results of our study suggest that obese and overweight children living in poverty reported a higher risk for mental health problems when compared with normal-weight children living in poverty. The psychosocial profile of this intra-racial group by weight category indicates higher scores in both internalizing and externalizing problems for obese boys and girls. While problems were more frequent among children in the 10-13 and 14-16 age groups, the interaction of the variables of weight category and age grouped suggest more problems in the overweight group of 10-13 years old.

Overweight or obesity among children living in poverty had an effect on their emotional and behavioral problems. Poverty by itself places children at risk of emotional and behavioral problems. In addition, poverty has an effect on obesity prevalence, with higher levels of obesity linked to lower socio-economic status. ${ }^{32}$ While race and ethnicity may affect the relationship between socio-economic status and obesity, consideration of intra-racial differences and accounting of disparities can better explain the results.

Disparities tend to have a stacking effect; usually, poverty is not the only disadvantage that a child confronts. Violence, lack of a healthy lifestyle or cognitive stimulation, parental unemployment, and/or lack of social opportunities surround the lives of these children. Our assumption about the low effect size reported in this study is that the psychosocial profile obtained in this sample might not be completely explained by their weight status and poverty levels. Instead, it is possible that obesity is one of many other factors that contribute to the mental health of children along with the possible additive effect of other disparities. ${ }^{33}$ Yet, there are important implications for the health care of children when considering both intra-racial group differences among ethnic groups, as well as the hidden combined effects that the exposure to disparities can have on a child.

Strategies to prevent childhood obesity in the primary care level and future consequences have not yet succeeded. This failure suggests the need to explore different types of healthcare delivery for those confronted by disadvantages.
The current healthcare system is not currently providing the additional support needed by families that confront disparities encountered mostly among minority groups or those living in poverty. ${ }^{34}$ This additional support is needed to help families confronting disparities reduce the continuous and systematic exposure to health risks. ${ }^{35}$

There are limitations in this cross-sectional study that include the causal relationship between obesity and psychosocial and behavioral problems: Did overweight and obesity lead to psychosocial problems, or did psychosocial problems lead to inactivity and/or overeating, which then lead to obesity? In addition, due to the restriction on only selecting children with three clinical measurements, there is a possibility that the prevalence of overweight and obesity in this population of Mexican-American children living on the border was higher than we report. Because this was not a comparison with children of higher SES, we cannot assume that the results found are not similar in all Mexican-American children. Previous research has well established the consequences of obesity for physical health; however, the impact of obesity on psychological well-being is less clear. ${ }^{17}$ Despite the limitations of this study, we found that obese and overweight children living in poverty reported a higher risk for mental health problems than did normal-weight children living in poverty.

Regular care offered to these children from intra-racial groups need an additional investment including a systematic support for their families, perhaps through parent education, that will remediate the effects of environmental risk exposures (violence, addictions, etc.) and encourage changes to their unhealthy lifestyles (obesogenic, sedentary, addictions, etc.). ${ }^{36}$ In addition, it is necessary to provide families with simultaneous management of their comorbid conditions in order to effectively prevent and treat these problems. Addressing only one problem (e.g. obesity) might not result in the best outcome due to the co-existence of other problems (e.g. mental health).

This study suggested that Mexican-American children living in poverty may represent an intra-racial group. Morbidities and co-morbidities confronted by these intra-racial groups of children are common not only among Mexican or Mexican-American children, but also among all children living under these conditions. Research studies must consider children's race-class groups instead of only classifying them by their racial group to improve the accuracy of their findings. The range of cultural and family characteristics can only partially explain differences between racial or ethnic groups; however, these differences could be better explained by taking into consideration the diverse profiles among individual race/ethnic groups. ${ }^{37,38}$

Future studies should focus on strategies for further understanding the possible implications in research and clinical care of intra-racial differences among Mexican-American children confronted by disparities. 


\section{Funding}

This study was funded by the Department of Pediatrics - Texas Tech University Health Sciences Center.

\section{Conflict of interests}

All authors have no conflict of interest to declare.

\section{REFERENCES}

1. Kit BK et al. Prevalence of and trends in dyslipidemia and blood pressure among US children and adolescents, 1999-2012. JAMA Pediatr 2015;169(3):272-279.

2. Nobili $\mathrm{V}$ et al. Nonalcoholic fatty liver disease: a challenge for pediatricians. JAMA Pediatr 2015;169(2):170-176.

3. Kaczorowski J. Chronic health conditions and obesity among children and youth. JAMA 2010;303(19):1915: author reply 1915:5-6.

4. Vincent HK et al. Outpatient rehabilitation outcomes in obese patients with orthopedic conditions. Eur J Phys Rehabil Med 2013;49(3):419-429.

5. Barquera Cervera $\mathrm{S}$ et al. Obesity in Mexico: epidemiology and health policies for its control and prevention. Gac Med Mex 2010;146(6):397407.

6. I'Allemand-Jander D. Clinical diagnosis of metabolic and cardiovascular risks in overweight children: early development of chronic diseases in the obese child. Int J Obes (Lond) 2010;34(Suppl 2):S32-S36.

7. Viner RM et al. Childhood body mass index (BMI), breastfeeding and risk of Type 1 diabetes: findings from a longitudinal national birth cohort. Diabet Med 2008;25(9):1056-1061.

8. Ogden CL et al. Prevalence of overweight and obesity in the United States, 1999-2004. JAMA 2006;295(13):1549-1555.

9. Mier $\mathbf{N}$ et al. Bridging research and policy to address childhood obesity among border Hispanics: a pilot study. Am J Prev Med 2013;44 (Suppl 3):S208-S214.

10. Ogden CL et al. Prevalence of obesity and trends in body mass index among US children and adolescents, 1999-2010. JAMA 2012;307(5):483490.

11. JP G et al. Encuesta nacional de salud y nutrición 2012. Resultados nacionales. Instituto Nacional de Salud Pública. Cuernavaca, México: 2012.

12. Halfon N, Larson $K$, Slusser W. Associations between obesity and comorbid mental health, developmental, and physical health conditions in a nationally representative sample of US children aged 10 to 17. Acad Pediatr 2013;13(1):6-13.

13. Wilson WJ. The Declining significance of race: Revisited \& revised. Tercera edisión. Londres: The University of Chicago Press; 2012; p.283.

14. Elmelech Y. Determinants of intragroup wealth inequality among whites, blacks \& Latinos. Wealth accumulation and communities of color in the United States: Current issues. Ann Arbor: The University of Michigan Press; 2006.

15. Tiffin PA et al. Modelling the relationship between obesity and mental health in children and adolescents: findings from the Health Survey for England 2007. Child Adolesc Psychiatry Ment Health 2011;5:31.

16. Mustillo $\mathrm{S}$ et al. Obesity and psychiatric disorder: developmental trajectories. Pediatrics 2003;111(4 Pt 1):851-859.

17. Wardle J, Cooke L. The impact of obesity on psychological well-being. Best Pract Res Clin Endocrinol Metab 2005;19(3):421-440.

18. Drukker $\mathrm{M}$ et al. A community study of psychosocial functioning and weight in young children and adolescents. Int J Pediatr Obes 2009;4(2):91-97.

19. Viner RM et al. Body mass, weight control behaviours, weight perception and emotional well being in a multiethnic sample of early adolescents. Int J Obes (Lond) 2006;30(10):1514-1521.

20. De la Cruz-Sanchez E et al. Sedentarismo, obesidad y salud mental en la población española de 4 a 15 años de edad. Rev Española Salud Pública 2011;julio-agosto: 373-382.

21. Banis HT et al. Psychological and social adjustment of obese children and their families. Child Care Health Dev 1988;14(3):157-173.

22. Perea-Martinez A et al. Obesidad y comorbilidades en niños y adolescentes asistidos en el Instituto Nacional de Pediatría. Acta Pediátrica México 2009;30(3):167-174.

23. Onyike $\mathrm{CU}$ et al. Is obesity associated with major depression? Results from the Third National Health and Nutrition Examination Survey. American J Epidemiology 2003;158(12):1139-1147.

24. Borges $\mathrm{G}$ et al. Body mass index and its relationship to mental disorders in the Mexican Adolescent Mental Health Survey. Salud Pública México 2010;52(2):103-110.

25. Brewis A. Biocultural aspects of obesity in young Mexican schoolchildren. Am J Hum Biol 2003;15(3):446-460.

26. Achenbach TM, R LA. Manual for the ASEBA Preschool and SchoolAge forms and Profiles. Burlington, VT: University of Vermont, Department of Psychiatry; 2001.

27. Leiner $\mathrm{M}$ et al. Psychometric comparisons of the Pictorial Child Behavior Checklist with the standard version of the instrument. Psychol Assess 2010;22(3): 618-627.

28. Ang RP et al. Examining the criterion validity of CBCL and TRF problem scales and items in a large Singapore sample. Child Psychiatry Human Development 2012;43(1): 70-86.

29. Buchalter D. Differences between children with ASDs, their nonASD siblings, and the CBCL normative sample based on CBCL profile scores. Houston: University of Houston; 2011.

30. Patriquin MA et al. Broad implications for respiratory sinus arrhythmia development: Associations with childhood symptoms of psychopathology in a community sample. Developmental Psychobiology 2015;57(1):120-130.

31. Cohen J. Statistical power analysis for the behavioral sciences. Segunda edición. New York: Academic Press; 1988.

32. Singh GK et al. Dramatic increases in obesity and overweight prevalence and body mass index among ethnic-immigrant and social class groups in the United States, 1976-2008. J Community Health 2011;36(1):94-110.

33. Anda $\mathbf{R}$ et al. Adverse childhood experiences and frequent headaches in adults. Headache: J Head Face Pain 2010;50(9):1473-1481.

34. Skelton JA et al. Prevalence and trends of severe obesity among US children and adolescents. Acad Pediatr 2009;9(5):322-329.

35. Shackleton N, Hale D, Viner RM. Trends and socioeconomic disparities in preadolescent's health in the UK: evidence from two birth cohorts 32 years apart. J Epidemiol Community Health 2016;70(2):140146.

36. Falconer CL et al. Can the relationship between ethnicity and obesity-related behaviours among school-aged children be explained by deprivation? A cross-sectional study. BMJ Open 2014;4(1):e003949.

37. Zilanawala A et al. Race/ethnic disparities in early childhood BMI, obesity and overweight in the United Kingdom and United States. Int J Obes (Lond) 2015;39(3):520-529.

38. Darmon N, Drewnowski A. Does social class predict diet quality? American J Clinical Nutrition 2008;87(5):1107-1117. 